\section{A PRESENÇA DO MÉTODO NAS DEFINIÇÕES INICIAIS DA PARTE II DA ÉTICA DE ESPINOSA}

Sérgio Luís Persch*

Resumo: Espinosa começa a sua Ética com uma série de definições, em virtude do modelo geométrico de raciocínio que ele incorpora sistematicamente à filosofia. Assim, os comentadores analisam minuciosamente o conjunto das definições que abrem a Primeira Parte, mostrando que elas cumprem de maneira exemplar a exigência do método. Já na Segunda Parte da Ética, os mesmos comentadores manifestam dificuldade em reconhecer fidelidade irrestrita ao método. Porém, trata-se de uma dificuldade aparente. Este artigo enfoca as definições iniciais da parte II da Ética, tendo por objetivo explicitar que elas se relacionam entre si de acordo com uma disposição formal precisa. Portanto, elas são escritas conforme o modelo matemático de raciocínio que Espinosa segue desde o começo da Ética.

Palavras-chave: Espinosa, Ética, definições, corpo, mente.

\section{1) Introdução: o recurso do raciocínio matemático}

Grande parte dos estudos relativos à obra de Espinosa procura explicitar a sistematicidade, que é uma das suas características proeminentes, devida ao modelo matemático seguido na elaboração dos textos. A realização mais perfeita desse empreendimento metodológico é a Ética. Seu caráter sistemático pode ser logo notado tendo-se em vista a maneira como é escrita: consiste num longo encadeado de proposições que se demonstram umas pelas outras, com base num conjunto de definições

* Professor da UFPB iniciais e de axiomas. Porém, mesmo notando desde logo essa peculiaridade ao primeiro contato com a obra, o leitor não apreenderá tão facilmente o efeito de conjunto causado pelo método. Por isso, o exame minucioso da maneira como o texto se articula exige um longo estudo, que pode ser feito tendo em vista a obra em seu todo ou, pelo menos, uma de suas partes na íntegra. O exemplo mais conhecido desse tipo de trabalho certamente é o de Guéroult. Resultado indiscutível da análise de Guéroult é a constatação de que precisamos fazer uma leitura estritamente sistemática das grandes obras do racionalismo, tomando uma medida disciplinar rigorosa que exige assiduidade e a total entrega do leitor ao texto investigado (GUÉROULT 5, p.9-16). Mas é improvável que todos os leitores, em qualquer momento, disponham de condições adequadas para tal trabalho de fôlego. Por isso, gostaríamos de encontrar, dentro do grande sistema de demonstrações da Ética, passagens pontuais em que, de maneira simples e como que intuitiva, apareça determinada operação racional que caracterize precisamente a maneira como Espinosa raciocina, utilizando recursos provenientes das matemáticas. Pensamos ser possível focar um ponto específico, explicitar um caso determinado de articulação do texto. Tais enfoques se mostram interessantes, na medida em que são capazes de tornar mais claras certas passagens da obra que um estudo abrangente, por mais minucioso que seja, passa por alto.

Inicialmente, faremos um breve contexto no qual a questão emerge, baseando-nos em dois intérpretes referenciais de Espinosa: Martial Guéroult e Marilena Chaui. ${ }^{1}$ Ambos desenvolveram estudos amplos e profundos da Ética. Instruem o leitor no que diz respeito ao caráter sistemático da obra, fazem análises densas das partes I e II. No caso da primeira parte, Guéroult cuida de explicitar a orientação metódica das definições iniciais, que reconhece evidentes por si mesmas (nota per se), exceto a definição VI - do ente absolutamente infinito - a qual demandaria de uma posterior 
demonstração. Marilena Chaui aborda criticamente a interpretação de Guéroult, mostrando que há uma unidade mais coesa, a partir da qual o conjunto de definições concorre para uma só definição: justamente, a do ente absolutamente infinito, causa de si e de todas as coisas.

No que concerne à segunda parte da Ética, Guéroult começa expondo as dificuldades de se perceber, no enunciado das definições, uma coesão e fidelidade ao método que se verifica na primeira parte e se torna exigência fundamental da obra. Em resposta às objeções enumeradas inicialmente, ele procura razões no desenvolvimento das partes I e II, considerando inclusive que motivações subjetivas podem ter concorrido para a enumeração aparentemente aleatória das definições. Em contrapartida, Marilena Chaui novamente mostra que há uma ordem mais rigorosa no enunciado das definições, perfeitamente justificável, tendo-se em vista o que foi desenvolvido na primeira parte e o que virá à frente, na parte II. Embora as duas interpretações sejam distintas e Marilena Chaui afirme uma unidade mais rigorosa tanto nas definições da primeira quanto nas da segunda parte da Ética, ambos recorrem a motivos externos aos enunciados mesmos das definições que abrem a parte II para justificálas, após mostrarem que a unidade das definições da primeira parte se compreende por elas mesmas.

Nós queremos apontar um elemento de articulação que se encontra sob o texto das quatro definições iniciais da parte II, até agora ainda despercebido. Assim, não pretendemos chegar a um resultado fundamentalmente distinto, mas pensamos tornar mais palpável um motivo metodológico rigoroso no começo da segunda parte, que ajudará a compreender melhor tanto a articulação dela com a parte I, quanto o ordenamento metódico dessas quatro definições. Queremos mostrar que as quatro definições se ordenam conforme um esquema muito caro a Espinosa, o mesmo utilizado na matemática para definir determinado valor mediante a regra da proporcionalidade.

Há uma passagem importante no Tratado da emenda do intelecto, na qual Espinosa lança mão desse recurso metodológico, explicando também o seu funcionamento. Logo após expor os quatro modos de percepção, ele explica cada um em separado subscrevendo-lhe exemplos, mas em seguida explica como os quatro modos ocorrem a partir de um só problema, qual seja: "dados três números, pergunta-se por um quarto número que esteja para o terceiro como o segundo está para o primeiro" (SPINOZA 7, TIE §23, G II 11)². Esse problema matemático pode ser percebido por quaisquer dos modos: ouvir dizer, experiência vaga, razão e intuição. Todos eles conduzem ao mesmo resultado correto. Porém, a qualidade do pensamento muda quando são diferentes os modos de pensar e, claro, trata-se também de um pensamento distinto quando somos capazes de perceber a mesma solução pelos quatro modos.

Seria difícil exagerar no dizer da importância desse exemplo matemático apresentado como que no núcleo do Tratado da emenda do intelecto. Já dispomos de muitos comentários sobre o assunto. Para o nosso propósito, basta indicá-lo e, em seguida, o que pretendemos é chamar atenção para o uso constante desse recurso em vários outros momentos em que, no entanto, Espinosa mantém o procedimento oculto sob a aparição explícita dos termos que são colocados em relação. Faremo-lo apresentando um exemplo só, que poderá contribuir para a interpretação deste momento difícil da Ética: a aparente descontinuidade do plano da obra, de feição matemática, no começo da parte II. Antes disso, é importante ressaltar a importância das definições que abrem a primeira parte da Ética, pelas quais se reconhece imediatamente o modelo matemático de raciocínio. 


\section{2) A parte I da Ética, uma exposição metódica exemplar}

As definições que abrem a parte I constituem um traçado geral, esboço ao qual se segue a construção more geometrico do sistema. Devido, em parte, à sua importância na economia geral do sistema, mas também devido ao seu caráter radicalmente distinto do que geralmente até então havia sido aceito com relação às coisas definidas, essas definições deram ensejo a infindáveis debates. Elas compreendem os principais problemas do espinosismo, tais como a noção de causa sui, o uso não convencional de categorias fundamentais como substância e atributo, a definição de Deus e a identificação da liberdade com a necessidade. Mas, apesar de haver interpretações divergentes, os comentadores são praticamente unânimes em aceitar a importância primordial das definições e, no que diz respeito ao método, do seu ordenamento.

A primeira definição é a da causa de si, a segunda é a de coisa finita. Em seguida, lemos as definições de substância, atributo e modo. A sexta definição é a de Deus. A sétima, da liberdade e a oitava, da eternidade.

Se, em termos de conteúdo e do emprego inusitado de noções de metafísicas consagradas pela tradição, as definições parecem desconcertantes, a lista no entanto parecerá "natural, porque ela é comandada pelo método" (GUÉROULT 5, p.20). O modelo provém da geometria. As definições são "explicações bem curtas de termos e de nomes pelos quais serão designados os objetos de que será tratado" (SPINOZA 7, PPC, G I 128). Entretanto, elas não somente se referem aos elementos simples, mas constituem como que os ângulos com os quais se desenha o esboço do assunto que se desdobrará no corpo do texto. Isso fica subentendido, por exemplo, na leitura de Guéroult, quando ele afirma que as cinco definições iniciais consistem num esboço das diferentes etapas da gênese da idéia de Deus. A principal definição - a $6^{\circ}$, de Deus - não seria nota per se, tal como as outras. Por isso, ela precisaria de uma subseqüente demonstração (dada na proposição11). Mas cabe perguntar se a articulação das diversas definições não basta para que o conjunto (portanto, também a $6^{\text {a definição) }}$ seja evidente por si mesmo.

Um estudo sumário e bastante esclarecedor acerca da unidade das definições que abrem a parte I da Ética é o de Marilena Chaui (CHAUI 2, p.7-28). Ao mostrar que o conjunto das definições "constituem uma só definição real" (CHAUI 2, p.20), ela insiste na importância de se compreender essa unidade das várias definições. No caso, a definição de Deus é "geometricamente construída com os elementos fornecidos pelas sete outras, todas elas dependentes da definição de causa de si e articuladas internamente a ela" (CHAUI 2, p.17). Tomadas em conjunto, as definições oferecem "a idéia complexa do absoluto" (CHAUI 2, p.13). Justamente por isso, é fundamental perceber a sua articulação interna, donde resulta o conjunto, ou melhor, a definição única do ser real. Com efeito, se tomássemos as definições em separado, cada uma seria meramente relativa, em particular a definição de Deus, antecedida por cinco outras, das quais então dependeria. Em vez disso, a percepção do conjunto uno intuitu (CHAUI 2, p.20) proporcionaria desde já um conhecimento intuitivo que se desdobrará nas proposições e respectivas demonstrações que perfazem a parte I.

Embora Marilena Chaui mostre a articulação interna das definições lançando mão do conteúdo que cada uma exprime e pelo qual remete a outras, é importante ressaltar que ela também chama atenção para o efeito da mera disposição formal do texto. As definições combinam-se umas com as outras de acordo com as leis da dióptrica familiares a Espinosa. ${ }^{3}$ Outra referência importante, no que diz respeito à disposição formal do texto, é a doutrina dos modos de pensar: percebendo-se a mesma coisa pelos diversos modos, devidamente relacionados entre si, obtém-se o 
conhecimento intuitivo dela. ${ }^{4}$

O modelo matemático é uma exigência observada com grande rigor ao longo de toda a primeira parte da Ética, que, nesse sentido, pode ser considerada uma exposição exemplar. Ao longo da parte I da Ética, Espinosa deduz a natureza e as propriedades da substância única constituída de atributos infinitos. Cada atributo é infinito em seu gênero e, inclusive, deve ser concebido por si mesmo, na medida em que o intelecto os percebe como constituindo a essência da substância. Dessa forma, os atributos são concebidos como realmente distintos uns dos outros, sem no entanto constituírem a essência de substâncias diferentes. É que, no caso, uma e a mesma substância se exprime seja mediante um atributo, seja mediante outro. Cada atributo exprime, à sua maneira, o ser da substância. Tanto quanto o pensamento, a extensão é um atributo da substância única e infinita. A extensão é infinita em seu gênero e, nesse sentido, ela não é limitada pelo pensamento ou por qualquer outro atributo. Após demonstrar que Deus é a substância única, na proposição 15 ele afirma: "Tudo o que existe, existe em Deus, e sem Deus, nada pode existir nem ser concebido" (SPINOZA 7, G II 56). A proposição se refere também a todas as coisas extensas. Espinosa concorda que seria um absurdo atribuir a Deus um corpo e uma alma, à semelhança do homem. No entanto, ele discorda daqueles que procuram remover completamente a extensão da natureza divina. Pois, considerada em si mesma, a extensão é infinita, não carecendo das limitações que os corpos particulares e finitos possuem. A extensão é um dos infinitos atributos de Deus.

A definição de modo será fundamental para explicar a maneira como as coisas particulares são produzidas, enquanto modificações da substância. Nenhuma coisa particular existe por si, tampouco é concebida por si mesma, pois neste caso ela seria uma substância. Todas as coisas particulares são partes da substância única. Com base na proposição
15 e também na definição de modo, citada acima, Espinosa escreve no corolário da proposição 25 que "As coisas particulares nada mais são que afeç̧ões dos atributos de Deus, ou seja, modos pelos quais os atributos de Deus se exprimem de maneira certa e determinada" (Id., ibid., p.68). $\mathrm{E}$ assim, até o final da primeira parte, fica demonstrada a maneira como o ser absolutamente infinito, na medida em que é causa de si, é também causa de todas as coisas particulares segundo uma ordem necessária, pelo que se conclui serem todas as coisas determinadas pelas leis necessárias da Natureza. No plano estritamente metafísico, a exposição sistemática da idéia do ser absolutamente infinito, causa de si e de todas as coisas, já é completamente desenvolvida na primeira parte da Ética.

\section{3) Sobre a articulação duvidosa das definições que abrem a parte II}

Nas outras partes da Ética (exceto a última, quejá não trazdefinições no começo), pode-se supor que as definições também se relacionam umas com as outras de maneira precisa e, tomados em conjunto, formam um todo. Somente notando esse seu caráter sistemático é que percebemos a importância do papel delas no desenvolvimento das respectivas partes de que constituem o começo. Porém, às vezes parece que Espinosa não está muito preocupado em conferir tal unidade às definições. Na segunda parte, por exemplo, o esboço inicial traçado pelo conjunto de definições parece não ser tão rigoroso pelo ponto de vista metodológico, e também não tão importante em termos de conteúdo. O leitor pode encontrar boas justificativas para essa descontinuidade, se tiver em conta o conteúdo particular que Espinosa submete a exame na parte II. Todavia, semelhantes justificativas também podem obstruir a descoberta de uma conexão mais 
rigorosa da segunda parte com a primeira, supondo precipitadamente uma insuficiência do método, uma incompatibilidade entre a exposição "metafísica" da primeira parte e essa espécie de "tratado" sobre as coisas práticas ou empíricas, que é a segunda parte. Vejamos algumas peculiaridades gerais da segunda parte, pelas quais possamos identificar as diferenças com relação à primeira.

Qual seria propriamente a inflexão da parte II no sistema da Ética? Tentaremos mostrar que nela Espinosa passa a considerar as coisas finitas em sua existência efetiva, isto é, tais como existem na prática, ou então, como nos são dadas na experiência. Assim, a parte I será invocada para garantir um conjunto de pressupostos axiomáticos, de leis necessárias segundo as quais a existência das coisas finitas e, especificamente, do ser humano, é definida. Porém, a entrada em cena das coisas finitas e do homem se afirma por simples constatações de fato. Isso obviamente acarretará uma série de características curiosas, como por exemplo, a de que os axiomas da parte II não são axiomas no sentido convencional, mas sim, "verdades de fato" ou "ensinamentos da experiência" (conforme as expressões de GUÉROULT 6, p.31). Mas a experiência admitida inicialmente como um dado será metodicamente explicada pelo processo demonstrativo que garante a continuidade entre as partes I e II da Ética.

A parte II inicia com um pequeno prefácio, que lembra a maneira como Espinosa introduz os assuntos nos Tratados que escreveu. Diz que vai explicar aquelas coisas que seguem necessariamente da essência de Deus e, em particular, "aquelas que possam nos conduzir, como que pela mão, ao conhecimento da mente humana". Trata-se, pois, de explicar a mente humana como uma coisa singular. Ela terá que ser explicada, então, como idéia particular de um corpo particular existente em ato e, ao mesmo tempo, como modificação das substância única, ou seja, ela é uma idéia singular e determinada de Deus. A experiência imediata que a mente humana possui de si própria não compreende a idéia de que ela é uma modificação determinada da substância única. Percebendo-se isolada, ela tem um conhecimento mutilado de si mesma. Mas essa inadequação não se deve ao fato de ela estar ligada ao corpo. Pelo contrário, é por meio da explicação de que a mente humana é idéia do corpo que Espinosa a demonstra como parte da Natureza, modificação da substância única. Para tanto, é preciso explicar de que maneira a mente particular de um ser humano é a idéia do corpo humano, e de que maneira ela exprime a essência do corpo. Essa é a principal tarefa da parte II da Ética.

O pensamento e a extensão são atributos de Deus, ou seja, Deus é uma coisa pensante e uma coisa extensa. É o que consta nas duas primeiras proposições, demonstradas com base na parte I da Ética: tanto os pensamentos quanto as coisas extensas são modos que exprimem a natureza divina de uma certa maneira e, enquanto tais, envolvem respectivamente os atributos pensamento e extensão. Não há qualquer primazia de um atributo sobre o outro. Ambos igualmente exprimem a essência divina, cada atributo à sua maneira. Na proposição 6 lemos que "Os modos de qualquer atributo têm Deus por causa, enquanto ele é considerado exclusivamente sob o atributo do qual eles são modos e não enquanto é considerado sob algum outro atributo" (SPINOZA 7, E, G II 89). Na proposição 7, por sua vez, encontramos o fundamento da famosa doutrina do paralelismo: "A ordem e a conexão das idéias é a mesma que a ordem e a conexão das coisas" (Id., ibid.). Pois a potência de pensar de Deus é igual à sua potência de agir. Num escólio, Espinosa afirma que "a substância pensante e a substância extensa são uma só e a mesma substância, compreendida ora sob um atributo, ora sob outro" (Id., p.90). Assim, também um modo da extensão e a idéia desse modo são uma só e a mesma coisa, mas que se exprime de duas maneiras distintas. Por isso há uma e a mesma conexão de todas as coisas. Na totalidade da extensão, há um encadeamento causal 
que corresponde precisamente ao encadeamento de idéias que constitui a totalidade do pensamento. A unidade de ambos é garantida pela substância única. Mas não há qualquer relação causal entre as coisas extensas e as idéias, uma vez que a causa de qualquer coisa extensa há que ser outra coisa extensa, e a causa de uma idéia particular há de ser outra idéia. Nesse sentido, Espinosa é mais radical que Descartes quanto à impossibilidade de uma relação causal entre extensão e pensamento, corpo e mente. Tese que se sustenta com base naquelas coisas universais que foram deduzidas acerca da causalidade imanente da Substância, na primeira parte. Agora, em meio a essas leis que perpassam a natureza toda, tanto na ordem do pensamento quanto na ordem da extensão, há que se tratar da natureza humana em particular e de maneira palpável. Essa é a tarefa específica da parte II, da qual não poderia ter dado conta a metafísica da Substância única desenvolvida na parte I. Veremos que as definições circunscrevem esse espaço em que se configura a existência do ser humano, constituído de corpo e mente. A maior dificuldade está em compreender como Espinosa, partindo da Substância única e infinita, chega à determinação efetiva da existência dos modos finitos, em particular do homem.

À primeira vista, Espinosa tem dificuldades no articular as partes I e II da Ética. O próprio texto, desde o começo da segunda parte, parece trair os pressupostos metodológicos seguidos com rigor na primeira parte. Já nas definições encontramos dificuldades, que cumpre anotar inicialmente. Todavia, cabe perguntar se não há uma ordem rigorosa que preside as definições da parte II. Tentaremos responder afirmativamente a essa questão.

As quatro definições iniciais da parte II são as seguintes:

I. Por corpo entendo um modo que exprime, de maneira certa e determinada, a essência de Deus, enquanto considerada como coisa extensa. Veja-se o corol. da prop. 25 da parte I.
II. Digo pertencer à essência de certa coisa aquilo que, se dado, a coisa é necessariamente posta e que, se retirado, a coisa é necessariamente retirada; em outras palavras, aquilo sem o qual a coisa não pode existir nem ser concebida e vice versa, isto é, aquilo que sem a coisa não pode existir nem ser concebido.

III. Por idéia entendo um conceito da mente, que a mente forma porque é uma coisa pensante.

Explicação. Digo conceito e não percepção, porque a palavra percepção parece indicar que a mente é passiva com relação ao objeto, enquanto conceito parece exprimir uma ação da mente.

IV. Por idéia adequada entendo uma idéia que, enquanto considerada em si mesma, sem relação com o objeto, tem todas as propriedades ou denominações intrínsecas de uma idéia verdadeira.

Explicação: Digo intrínsecas, para excluir a propriedade extrínseca, a saber, a que se refere à concordância da idéia com o seu ideado (SPINOZA, 7, E, G II 84-5)

Além dessas, lemos ainda a definição de duração, de realidade e de coisa singular. Porém, vamos nos ater às quatro definições iniciais, pois é a partir delas que identificaremos a ordem que preside o texto de Espinosa.

Podemos recorrer novamente a Guéroult, que nos indica os diversos problemas que saltam à vista numa primeira leitura e que dificultam reconhecer o procedimento irrestritamente sistemático utilizado no começo da segunda parte da Ética. Algumas das definições não são invocadas em toda a parte II. Outras parecem supérfluas, como, no caso, a definição de essência. Com efeito, na primeira parte Espinosa fala muito dela sem que precisasse defini-la previamente. Também ficou omitida a definição que pareceria a principal, qual seja, a definição de Mente. Outra parece muito estreita: a da idéia, definida simplesmente como algo que 
a mente forma. Aparentemente, elas não são enumeradas segundo uma ordem, pois, questiona Guéroult: "não se percebe à primeira vista por que o corpo deve ser definido antes da essência, a essência antes da idéia" (GUÉROULT, 6, p.26). O comentador procura justificar cada um desses problemas recorrendo ao que foi ou será desenvolvido, ou atribuindo as particularidades à intenção do autor, em torno da qual só podemos fazer algumas conjeturas. Embora as observações em torno de cada problema indicado sejam muito minuciosas e, quiçá, certeiras, gostaríamos de encontrar uma justificativa mais rigorosa para o ordenamento das definições, que satisfaça as exigências do modelo matemático, sem o qual a obra de Espinosa não se sustentaria.

Marilena Chaui também se ocupa com a "anomalia" que encontramos no começo da parte II: “ainda uma vez seremos surpreendidos com uma anomalia. Assim como o De Deus parecia não começar com a definição de Deus, o Da mente começa com a definição do corpo e nem mesmo traz uma definição da mente humana" (CHAUI 1, p.752). Para solucionar o problema, ela confronta sistematicamente o conjunto de definições das partes I e II, as da primeira dedicados ao ser absoluto e, da segunda, às coisas singulares.

Assim como a definição de corpo remete à parte I, Marilena Chaui mostra que as definições de idéia e idéia adequada também estão vinculadas ao desenvolvimento da primeira parte. Elas são modos do atributo pensamento, assim como os corpos são modos do atributo extensão. Dessa forma, "Espinosa oferece a ratio entre as definições de causa de si e de Deus e a definição dos seus efeitos modais como coisas singulares - com essa ratio evidencia-se a proporção entre o ser absolutamente infinito e as coisas singulares" (Id., p.755). Resta, pois, a "anomalia" relativa à falta de uma definição da mente e, não obstante isso, Espinosa vincula a idéia à mente, dizendo-as propriedades de uma coisa pensante que, no caso, não é definida. Ao subscrever as possíveis razões pelas quais não há essa definição de mente, Marilena Chaui apresenta a noção de coisa pensante ou mente humana como uma espécie de inflexão que ocorre na parte II da Ética, para que seja atingido seu escopo: a dedução da natureza e da origem da mente humana. Eis, em suma, as quatro razões: logicamente, a definição paralela à de corpo é a definição de idéia; ontologicamente, todo modo finito da extensão é um corpo, mas nem todo modo infinito do pensamento é uma mente (pois a mente se define a partir da complexidade das operações e afecções de um corpo); corpo e mente humanos têm que ser deduzidos na parte II, pois são modos determinados específicos dos atributos pensamento e extensão; há um propósito polêmico de fazer frente à perspectiva cartesiana, que supõe o conhecimento da mente anterior e independente do corpo. Essas razões, Marilena Chaui as obtém pela interpretação do desenvolvimento da parte II (Id, p.757). Perguntamo-nos se a disposição formal das quatro definições iniciais já não oferece o esboço desse desenvolvimento, garantindo a elas então uma unidade tão coesa quanto a das definições da primeira parte, as quais, juntas, concorrem para uma única definição (conforme vimos acima).

\section{4) A disposição formal das quatro definições iniciais da parte II}

Voltemos nossa atenção exclusivamente para as quatro definições iniciais e vejamos se não é possível depreender do texto uma razão precisa que justifique a ordem pela qual estão dispostas e, no caso, qual seria o efeito desse ordenamento racional na compreensão do significado de cada um dos termos definidos ou então, simplesmente, utilizados nas definições. 
Quanto à primeira definição, é interessante notar atentamente a remissão feita ao corolário da proposição 25 da parte I. Citamos acima o corolário da proposição 25 , no qual se conclui que as coisas particulares nada mais são do que afecções dos atributos de Deus, já que pela proposição 15 , tudo existe em Deus e é por ele concebido. Note-se, pois, que a definição de corpo mais parece uma proposição demonstrada na seqüência da parte I da Ética. Todavia, enquanto definição, ela exprime de modo positivo aquilo que, no começo da parte I, foi descrito simplesmente de maneira negativa: finita é uma coisa que se limita por outra da mesma natureza por exemplo, um corpo é limitado por outro corpo; o modo é em outro, pelo qual também é concebido (definições 2 e 5 da primeira parte). "Assim, o que é enfatizado agora é a natureza expressiva do modo (...) Na Parte I, a definição I,5 sublinha o modo como o estar em outro e ser concebido por outro, portanto, o modo no seio do absoluto; na parte II, a definição I, 1 sublinha o modo finito pelo exprimir a essência do ser absoluto de maneira certa e determinada, portanto, sua singularidade" (CHAUI 1, p.754). Vale ressaltar esse caráter positivo da definição de corpo enquanto modo certo e determinado da essência divina.

A segunda definição traz à tona um dos problemas cruciais do espinosismo, qual seja: a essência de cada coisa particular é, também, absolutamente singular. Pois assim como a supressão da essência suprime a coisa, assim também a coisa tem que estar dada para que seja dada a respectiva essência. Essa definição ou descrição da essência se apóia na definição de corpo. Pois cada corpo (mais simples ou mais complexo) tem um lugar certo e determinado (único) no encadeamento causal de todas as coisas. Portanto, uma essência jamais exprime um gênero ou espécie de corpos, e também não é através desses conceitos gerais que conhecemos a essência de um corpo particular. O conhecimento da essência de uma coisa determinada depende do conhecimento da sua causa, ou do encadeamento causal que a produz. As definições de corpo e de essência são, portanto, definições de coisas singulares.

À terceira definição, Espinosa acrescenta uma explicação. Há certas controvérsias quanto ao modo como devemos compreender essa explicação. Trata-se de saber se essa disponibilidade de ação que tem a mente para formar conceitos diz respeito àquela capacidade que ela possui de conhecer adequadamente as coisas - um conhecimento livre de paixões - ou se a ação da mente aqui definida é relativa a qualquer modo natural de formar conceitos, conforme os diferentes modos de percepção pelos quais ela conhece as coisas de maneira inadequada ou adequada. Não abordaremos nenhuma interpretação que já se fez em torno dessa questão, mas pretendemos sugerir que se trata do segundo caso. Ou seja: a ação pela qual a mente se move, conforme pressuposta na definição 3 , refere-se a qualquer tipo de conhecimento, tanto o inadequado quanto o adequado. ${ }^{5}$

A quarta definição também é acrescida de uma breve explicação, visando esclarecer melhor o critério de verdade que está sendo definido. Ele não se depreende da relação entre a idéia e o objeto conhecido. Não quer dizer que a adequação entre a idéia e o ideado esteja sendo questionada. Mas esta é, como diz Espinosa, algo extrínseco ao conhecimento em si mesmo. A adequação da idéia com o objeto é um resultado do conhecimento adequado. Pois conhecer adequadamente é ter uma idéia da qual conhecemos a causa, ou seja, sabemos como ela se produz no pensamento.

A figura que se delineia pelas quatro definições é aquele quadro de relações que Espinosa utiliza várias vezes nos seus argumentos. O exemplo que Espinosa oferece no Tratado da emenda do intelecto é o do cálculo da quarta proporcional: dois está para quatro assim como três está para seis. É claro que essa expressão matemática, quando aplicada a palavras ou imagens, jamais nos coloca diante de um problema de fácil solução, como é o das relações algébricas entre números. Todavia, a estrutura 
formal do raciocínio tem um efeito preciso sobre os termos envolvidos. Referimo-nos, acima, ao modo como Espinosa apresenta os quatro modos de percepção: o ouvir dizer, a experiência vaga, o conhecimento racional e o conhecimento intuitivo. Este último é o conhecimento perfeito e, por isso, mesmo, mais difícil de ser explicado. Contudo, obtemos uma noção do que seja o conhecimento intuitivo na medida em que entendemos a sua posição relativamente aos outros modos de percepção. Da mesma forma, a noção precisa de mente se depreende do conjunto das quatro definições iniciais da parte II da Ética.

Relacionemos, portanto, as quatro definições entre si.

A primeira definição é a de corpo. Caso tivéssemos em vista a coisa definida, seria deveras complicado entender por que tal definição ocupa esse lugar primeiro. Mas não nos deixemos ofuscar por uma noção prévia da coisa definida, pois temos que ficar atentos unicamente à definição e ao lugar que ela ocupa. Na definição mesma, Espinosa remete o leitor a uma passagem da parte I. Essa remissão à parte I não nos parece simplesmente indicar uma referência para se compreender melhor o teor da definição. Ela, na verdade, relaciona a primeira definição com o corolário da definição 25 da parte I, para estabelecer um ponto preciso de articulação entre as duas partes. O corolário nos diz, baseado numa cadeia de proposições, que as coisas particulares são afecções dos atributos de Deus, modos pelos quais os atributos de Deus se exprimem de maneira certa e determinada. Toda essa teoria é recolhida pela definição de corpo, sendo, pois, a partir desta que Espinosa explicará como, em particular, as coisas finitas seguem da essência infinita.

A par dessa articulação precisa da primeira definição com o encadeamento demonstrativo da parte I, pode-se notar que a segunda definição também se apóia na parte I da Ética e se enuncia como uma consequência direta da primeira definição. Pois é na proposição 25 da parte I, justamente, que Espinosa demonstra ser Deus a causa eficiente não apenas da existência das coisas, mas também de sua essência. Com efeito, se todas as coisas particulares são modificações da substância única, elas o são enquanto existência e essência particulares. Um corpo é uma essência singular expressiva.

Na terceira definição parece que Espinosa adota uma perspectiva inversa, numa espécie de oposição dualista entre corpo e mente. Pois, se a noção de essência se segue à definição de corpo, a definição de idéia se segue da noção de mente, a qual, por sua vez, não é definida. A mente, não sendo propriamente definida, aparece como "sujeito que tem idéias". Pela terceira definição só, não se percebe como a mente estaria articulada no processo contínuo de causalidade das coisas finitas a partir do ser infinito, como é o caso da definição de corpo. Deveras, não há de ser apropriado dar uma definição particular de mente, devido ao fato de se correr o risco de supô-la como um sujeito isolado e, assim, separada do mundo e livre das afecções corpóreas, tê-la como capaz de formar as idéias adequadas. ${ }^{6}$ Mas, conforme a nossa sugestão de leitura, a terceira definição de maneira alguma deve ser considerada à parte, e sim, articula-se com as demais. A mente não é definida porque, no delineamento matemático das quatro definições, ela é como que o termo incógnito $-\mathrm{x}$ - que se deduz a partir das relações de proporcionalidade entre os outros termos definidos. A mente não tem uma definição. Ela figura imediatamente no conjunto de definições, de modo que se precise deduzir delas isso o que a mente efetivamente é. Por motivos idênticos, o axioma "o homem pensa" aparece como uma verdade de fato ou um ensinamento da experiência (cf. o comentário de GUÉROULT 2, p.31 acerca do segundo axioma da parte II da Ética). É com ela que o homem aparece como dado na existência. Assumi-la como um primeiro princípio para, a partir dele, deduzir outras verdades implicaria em fazer dela uma hipóstase e, consequentemente, 
cair no erro do antropomorfismo. Em vez disso, e enquanto axioma, o "ser pensante" se explica como modificação da substância que se exprime enquanto extensão e pensamento. No caso das definições em questão ele afirma a identidade entre essência e existência com base na definição de corpo, articulada com as demonstrações da causalidade substancial da parte I da Ética, e relaciona a essência singular com a idéia adequada. Remove-se o erro quando se sabe que são inadequadas muitas idéias que por natureza mente possui. A verdade se alcança na medida em que se sabe distinguir as idéias adequadas e as ideais inadequadas (isto é, mutiladas e confusas). É pela definição 4 que chegamos a saber no que consiste o conhecimento adequado. Notemos que, nela, já não há qualquer referência à ação da mente. Pois o conhecimento verdadeiro consiste numa percepção adequada da idéia, considerada nela mesma. ${ }^{7}$ Uma idéia que se conhece como verdadeira por força das suas propriedades intrínsecas equivale àquela unidade entre essência e existência resultante das definições 1 e 2 . A idéia adequada exprime verdadeiramente a essência de uma coisa.

Observando, finalmente, o conjunto de definições em exame, podemos notar que, por um lado, a noção de essência está estreitamente vinculada com a definição de corpo e, por outro lado, a definição de idéia está relacionada com a noção de mente. Porém, no caso da terceira definição, há provisoriamente uma desproporção entre as idéias, enquanto conceitos que a mente forma para reter e explicar as coisas, e as próprias coisas, na medida em que as idéias assim concebidas podem ser inadequadas. Desproporção tanto mais evidente pelo fato de que a mente não é definida, mas aparece como um termo cujo sentido se define pelo papel que esse termo desempenha na definição. Porém, com a quarta definição se estabelece uma perfeita unidade entre o corpo enquanto expressão particular da essência divina, a essência particular de uma coisa dada, a idéia adequada por força das determinações intrínsecas que a tornam verdadeira e a mente que assim a percebe. Não havendo para a mente uma definição particular, ela figura como um t ermo que se define perfeitamente no quadro de relações que as definições constituem em conjunto. Portanto, também ali se reconhece o modelo matemático de que Espinosa se utiliza para conduzir ao conhecimento da mente humana.

\section{REFERÊNCIAS BIBLIOGRÁFICAS:}

1. CHAUI, Marilena. A nervura do real. Imanência e liberdade em Espinosa. São Paulo: Companhia das Letras, 1999.

2.

"A definição real na abertura da Ética I de Espinosa". In. Cadernos de História e Filosofia da Ciência, série 3, vol. 11. Campinas: UNICAMP, 2001.

3. ESPINOSA, Baruch de. Obras escolhidas. São Paulo: Abril Cultural, 1973.

4. Obras. Introducción, traducción, notas e indices de Atilano Domínguez. Madrid: Alianza, 1986.

5. GUÉROULT, Martial. Spinoza I: Dieu (Éthique, 1). Paris: Aubier-Montaigne, 1967.

6. S__ Spinoza II: l'Âme (Éthique, 2). Paris: Aubier-Montaigne, 1972.

7. SPINOZA. Opera. Im Auftrag der Heidelberger Akademie der Wissenschaften. Herausgegeben von Carl Gebhardt. Heidelberg: Carl Winter, 1925; 2. Auflage, 1972, 4bd.

8. SPINOZA, Benedictus de. Ética. Belo Horizonte: Autêntica, 2007

\section{The presence of the method in the initial definitions of part II of Spinoza's Ethics}

Abstract: Spinoza begins his Ethics with a series of definitions, because of the geometrical model of reasoning, which he incorporates systematically to the philosophy. So, the commentators analyze meticulously the assembly of definitions that open the First Part, showing that they fulfill exemplary the demand of the method. In the Second Part of the Ethics, on the contrary, the same commentators manifest difficulty 
in recognizing limitless fidelity to the method. However, it is an apparent difficulty. This paper focuses the initial definitions of the Second Part of the Ethics, having for goal to seat out that they are related among themselves according to a precise formal arrangement. Therefore, they are written in agreement to the mathematical model of reasoning that Spinoza follows since the beginning of the Ethics.

Keywords: Spinoza, Ethics, definitions, body, mind.

\section{NOTAS:}

1. Temos em vista os dois volumes que Gueroult escreveu sobre as partes I e II da Ética de Espinosa, respectivamente, e de Marilena Chaui, as passagens da Nervura do real que tratam do assunto e um artigo sobre "A definição real na abertura da Ética I de Espinosa" (cf. as referências bibliográficas no final do artigo).

2. Abreviamos os títulos das obras de Espinosa citadas, com as inicias: TIE-Tractatus de intellectus emendatione; PPC - Renati Des Cartes Principiorum Philosophiae; E - Ethica; KV-Korte Verhandeling; CM-Cogitata Metahpysica. A letra " $\mathrm{G}$ ” se refere à edição de Gebhardt, "II" se refere ao respectivo volume e o número "11", à página do texto.

3. Ele as discute numa carta a Jelles, a Epistula 39 (CHAUI 2, p.17).

4. Como já observamos acima, reencontraremos esse esquema nas quatro definições iniciais da parte II da Ética. A disposição formal do texto revela uma articulação que pelo conteúdo não parece óbvia.

5. Vale a pena notar uma passagem do Tratado breve, que, num enunciado muito parecido, diz outra coisa. Para se entender de que modo as afirmações da mente, quando ela conhece adequadamente, concordam de todo com a natureza da coisa conhecida, Espinosa afirma que "o entender... é um puro e simples padecer, ou seja, nossa mente é modificada de forma que recebe outros modos de pensar que não tinha anteriormente" (SPINOZA, KV parte II cap.16, G, I 83) O padecer não significa aqueles excessos passionais que mantêm a mente na ignorância. E, pelo contrário, a mente ativa pressuposta na definição 3 não se refere exclusivamente às ações da mente autônoma que conhece, mas a todo o modo natural de conhecimento.

6. A definição 3 permite considerar que os conceitos que a mente forma são modos de pensar que não correspondem a quaisquer entes verdadeiros (conforme as expressões utilizadas por Espinosa nos Pensamentos metafisicos). Os conceitos de gênero e espécie, de número e medida, as noções de término ou extremidade são modos de pensar utilizados pela mente para reter, explicar e imaginar as coisas (CM, I, 1; G-I, p.234).

7. É nesse sentido que Espinosa afirma, no Tratado breve, que o entender é um puro padecer, transformando-se a mente por força da idéia verdadeira, ao invés de essa se dobrar à vontade e ação da mente. 